opens up the world of climate science by showing the real data in accessible formats and by addressing key uncertainties. Its coverage of IPCC Working Groups I and III is outstanding, and I hope to see a second edition soon that does equal justice to Working Group II. I would also like to see the topics cross-referenced to the IPCC reports and an appendix of cited literature. A true guide to the IPCC assessment should offer the invested reader an entrée to the actual reports and the literature they probe.

I look forward to pulling out my 'Pocket IPCC' the next time I encounter a sceptical businessman or a congressional staffer who needs to know more about climate projections or the uncertainty surrounding climate sensitivity. It might even impress my friends at cocktail parties.
Published online: 9 0ctober 2008

doi:10.1038/climate.2008.109

\section{Jay Gulledge}

Jay Gulledge is a Senior Scientist and

Program Manager for Science \& Impacts at the Pew Center on Global Climate Change in Arlington, Virginia.

e-mail:gulledgej@pewclimate.org

\title{
On our bookshelf: dark visions
}

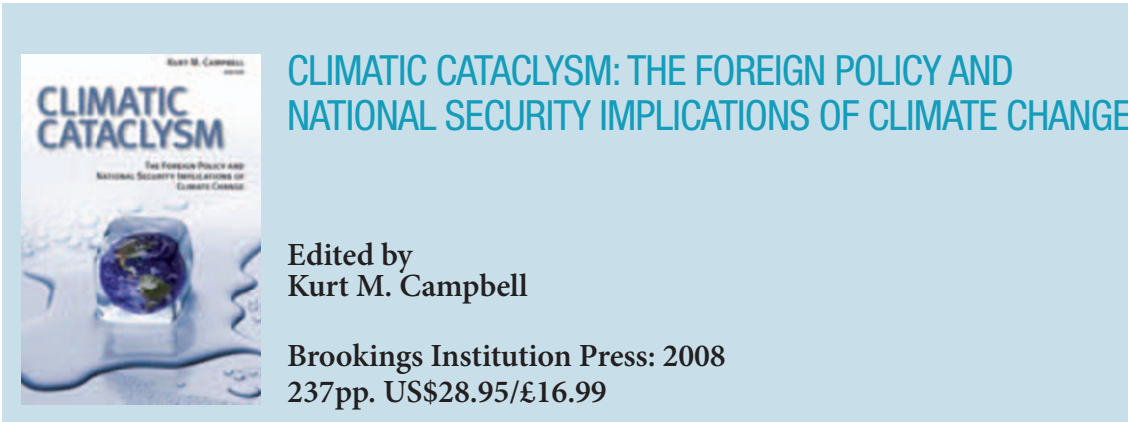

Crossing the terrain of science, society, fiction and futurism, a new crop of books imagines harrowing possible fates for humans in a greenhouse world. Among these varied narratives, Climatic Cataclysm stands out for its impressive $\mathrm{CV}$, originating in two years of discussions among 20 eminent experts on climate science, foreign policy and national security. Distilled from their talks are three possible scenarios of an altered Earth, ranging from the likely best case to the worst. In the first, moderate emissions cause warming of $1.3^{\circ} \mathrm{C}$ above the 1990 global average by 2040 , in line with the latest projections from state-of- the-art climate models. The second scenario pictures the temperature rise accelerated by feedback effects, and the third has the Earth passing a devastating tipping point later this century, producing cataclysmic change.

Acknowledging the great uncertainties in their projections but aiming for farsightedness, the authors soberly detail expected impacts and potential human responses. On their list are not just famine and pestilence but class war, the collapse of economies and the United Nations, and plummeting developed-world birthrates owing to "increasingly difficult living conditions and ... general loss of hope".

\section{THE LONG DESCENT: A USER'S GUIDE} TO THE END OF THE INDUSTRIAL AGE

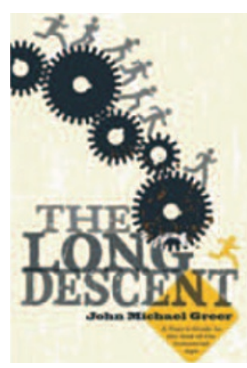

by John Michael Greer

New Society

Publishers: 2008

288pp. US\$18.95

\section{The Long Descent collects and} expands on essays by peak-oil blogger John Michael Greer, whose writing draws on his historical expertise and spiritual sensibility: Greer holds the title of Archdruid. He believes that climate change and energy shortages will bring on societal collapse, but not the kind many fear. Our culture's most deeply felt visions of the future - on one hand, irrepressible progress, and on the other, sudden catastrophe - are literally myths, Greer argues, with the same defining features as myths in other cultures. The reality will be the long, stepwise deterioration of the book's title, one that mirrors the decline of past civilizations.

That means a rapidly approaching global crisis decades long, followed by a recovery but then further crises. Each step in Greer's descent strips the human population of social and technological complexity, and the sequence ends with regression to a sustainable agrarian regime that none of us will live to see. His advice: neither global nor personal action can prevent this long descent, but a grassroots shift toward low-tech, low-energy and communityoriented lifestyles would soften the immediate blow.

\section{THE CARBON DIARIES 2015}

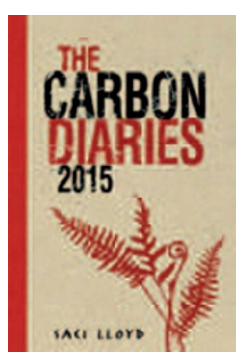

by Saci Lloyd

Hodder Children's

Books: 2008

384pp. $£ 6.99$

In this novel, a teenage girl's irreverent journal entries are the window into a society scrambling for footing in the face of climate change. With disastrous weather pounding the globe, the United Kingdom in 2015 becomes the first country to seize control of emissions with a comprehensive carbon-rationing scheme. To ride the bus, charge a phone or buy a bottle of Australian wine requires a swipe of the electronic ration card - and the only resort when credits run out is the black market. 
The chronicle of the initial year of rationing dwells on the punk band that 16-year-old Laura Brown plays bass in, her crush on the boy up the street, and her parents' marriage hitting the rocks when Dad loses his job in a failing economy. As Laura and her family muddle through more mundane crises, catastrophic droughts, storms and riots corrode the world around them.

\section{IN MEMORY OF CENTRAL PARK: 1853-2022}

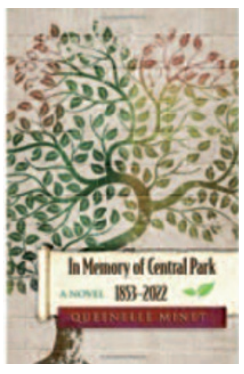

\section{by Queenelle Minet}

Synergy Books: 2008

251pp. US $\$ 13.95$

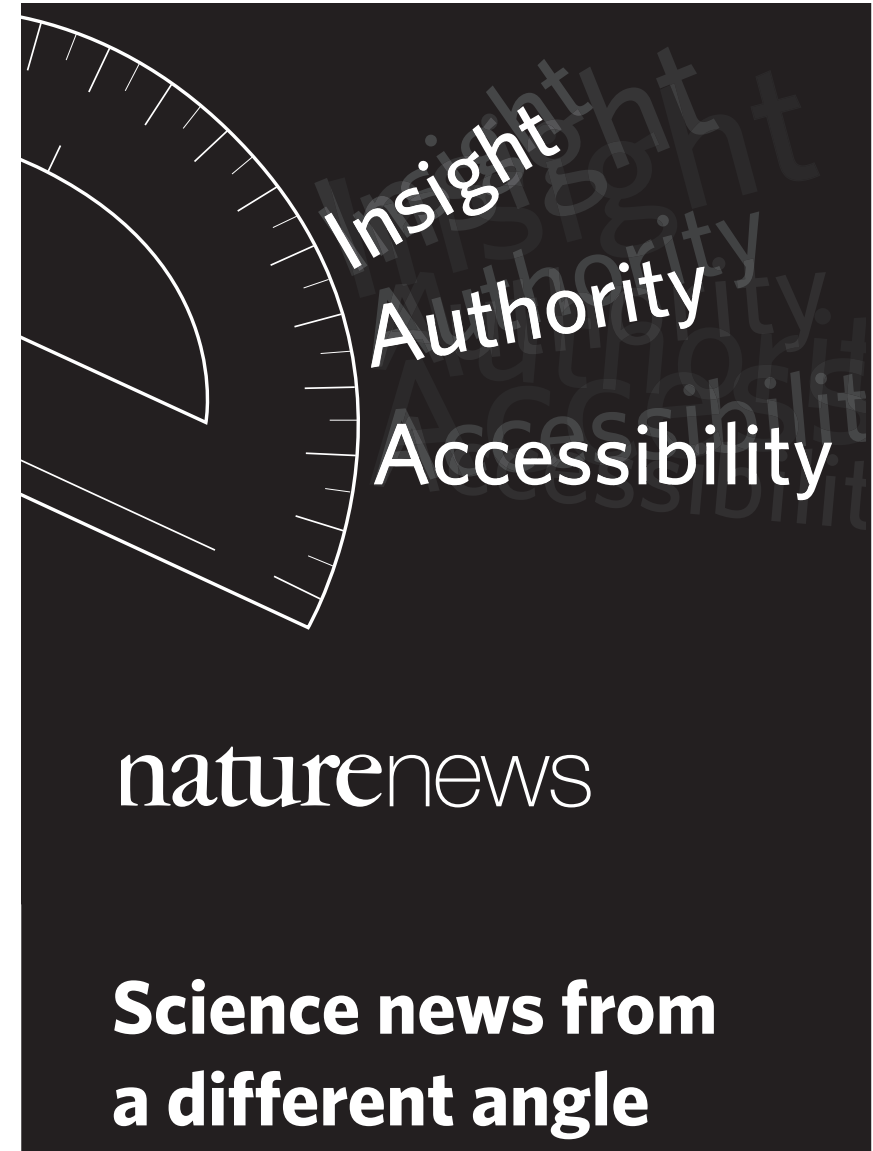

From daily science updates to investigative journalism, from community commentary to editorial opinions, Nature brings you the most in-depth science news coverage online.

Visit our new blog, The Great Beyond, for a comprehensive round-up and expert discussion of today's science news from around the world.

Subscribe to Nature and receive full access to Nature News as well as weekly issues of the most influential scientific journal in the world, in print and online.

www.nature.com/news 